\title{
ENTRE SIGNIFICAR E DECIFRAR A ESCRITA: A ALFABETIZAÇÃO DE IVO
}

\author{
Ana Maria Esteves Bortolanza (Universidade de Uberaba)* \\ Renata Teixeira Junqueira Freire (Universidade de Uberaba)**
}

\section{RESUMO}

Este artigo analisa gestos da escrita de uma criança de seis anos que frequenta o primeiro ano do Ensino Fundamental, período inicial de sua alfabetização, em 2015. Os dados coletados em uma entrevista informal fazem parte de um projeto de pesquisa institucional em andamento denominado $A$ formação da atitude autora e leitora no processo de apropriação da escrita na educação infantil, que se estendeu aos primeiros anos do ensino fundamental, tendo como objetivo compreender como as crianças se apropriam da escrita em contextos educativos formais e informais. Trata-se de uma pesquisa qualitativa, de caráter etnográfico, realizada por meio de observações, entrevistas e experimentos pedagógicos. Neste artigo analisamos os resultados de uma entrevista com Ivo, uma criança de seis anos cujos registros escritos analisados evidenciam o paradoxo entre significar a escrita na vida e decifrar o código alfabético na escola. Conclui-se que, embora a escola alfabetize priorizando o ensino do código alfabético, portanto o aspecto externo da escrita, a criança busca apropriar-se de sua significação social, atribuindo-lhe sentidos que são construídos no entorno da família e de outros contextos.

Palavras chave: Alfabetização. Cultura escrita. Significado e sentido. Anos iniciais do ensino fundamental.

\section{ABSTRACT}

\section{BETWEEN MEANING-MAKING AND DECODING WRITING: IV0'S LITERACY}

This article analyzes writing gestures of a six-year-old child who attends the first year of primary school, initial period of his literacy education (2015). The collected data during an informal interview are part of an institutional research project The development of authoring and reading attitude in the writing appropriation process in preschool, which has been extended to the first years

\footnotetext{
Doutora em Educação pela Universidade Estadual paulista (UNESP). Docente da Universidade de Uberaba (Uniube). Docente/ Pesquisadora do Programa de Pós-Graduação em Educação da Universidade de Uberaba (Uniube). Líder do Grupo de Estudos e Pesquisas Infância e Contextos Educativos (GEPICE/Uniube). E-mail: amebortolanza@uol.com.br

** Doutora pela Pontifícia Universidade Católica de São Paulo (PUC/SP). Docente/Pesquisadora do Programa de Pós-Graduação em Educação da Universidade de Uberaba (Uniube). Pesquisadora do Grupo de Estudos e Pesquisas Infância e Contextos Educativos (GEPICE/Uniube). E-mail: renatatjunqueirafreire@gmail.com
} 
of primary school, aiming to comprehend how children appropriate themselves of writing in formal and informal contexts. It is a qualitative research, with an ethnographic approach, carried out through observations, interviews and pedagogical experiments. In this article we analyze the results of an interview with Ivo, a child aged six whose written records analyzed clearly show the paradox between making meaning through writing in life and decoding the alphabetic code in school. It concludes that, although schools teach reading and writing by emphasizing the teaching of the alphabetic code, the external aspect of writing then, children seek to appropriate themselves of its social meaning, assigning to it senses which are constructed in the family environment and other contexts.

Keywords: Literacy. Written culture. Meaning and sense. Early years of primary school.

\section{RESUMEN}

\section{ENTRE SIGNIFICAR Y DESCIFRAR LA ESCRITURA: LA ALFABETIZACIÓN DE IVO}

Este artículo analiza los gestos de escritura de un niño de seis años de edad que asiste al primer grado de la escuela primaria, período inicial de su alfabetización (2015). Los datos recogidos en una entrevista informal son parte de un proyecto de investigación institucional La formación de la actitud de autor y la lectura en el proceso de escritura apropiación en la educación de la primera infancia, que se extendía hasta los primeros años de la escuela primaria, con el objetivo de entender cómo los niños escrito apropiado en entornos educativos formales e informales. Se trata de una investigación cualitativa, etnográfica, realizada a través de observaciones, entrevistas y experimentos educativos. En este artículo se analizan los resultados de una entrevista con Ivo, un niño de seis años que han analizado los registros escritos muestran la paradoja entre significar la escritura en la vida y descifrar el código de letras en la escuela. Llegamos a la conclusión de que, aunque la escuela alfabetizar priorizando la formación en el código alfabético, por lo que el aspecto externo de la escritura, el niño busca la propiedad de su importancia social, atribuyendo significados que se construyen rodea a la familia y otros contextos.

Palabras clave: Alfabetización. Cultura escrita. Significado y sentido. Primeros años de la escuela primaria.

\section{Introdução}

Este artigo se insere na problemática da apropriação da escrita pela criança em fase de alfabetização. Alfabetiza-se uma criança para inseri-la no mundo da cultura escrita. Isso é o que estudos vêm mostrando em muitas publicações e os discursos acadêmicos em eventos científicos têm reiterado.
O que entendemos por cultura escrita? O que é alfabetizar, significar a escrita ou decifrar o código alfabético?

A alfabetização envolve a apropriação de um conjunto de processos que precisa ser ensinado sistematicamente. Nessa perspectiva, entendemos que, diferentemente da aprendi- 
zagem da linguagem oral, não é suficiente que as crianças tenham nascido em um ambiente com a presença de escritos, onde vivem pessoas letradas, para que venham a aprender a escrever. São necessárias situações e atividades significativas que criem as condições adequadas para a aprendizagem da escrita, isto é, a imersão da criança na cultura escrita e a presença de mediadores para que ela se aproprie de conhecimentos sobre a escrita.

A cultura escrita é, para Viñao Frago (1999), um conjunto de objetos escritos que circulam na sociedade, por meio de diversos gêneros discursivos e suportes como revistas, livros, cadernos, jornais, panfletos, televisão, cinema, telas do computador, histórias em quadrinhos, outdoors e outros, e, também, as formas como esses escritos são assimilados nas práticas de leitura e escrita. Escrita e oralidade são, de acordo com esse autor, duas práticas culturais distintas, mas profundamente vinculadas, o que implica em ver ambas em suas relações.

[...] cada uma destas duas linguagens, a oral e a escrita, tem sua própria dinâmica e lógica interna, suas normas e consequências. Nem a escrita é a linguagem falada traduzida para o texto escrito - como se tratasse de uma gravação - nem a fala é a linguagem escrita incorreta ou desvalorizada. Ali, porém onde existe o escrito, nenhuma das duas linguagens pode ser entendida sem considerar suas interações e influências mútuas. (VIÑAO FRAGO, 1999, p. 137).

Compreendemos, nessa perspectiva, que a cultura escrita é uma prática cultural distinta da cultura oral, mas entre elas não há uma dicotomia, uma vez que a oralidade é uma dimensão constitutiva da cultura escrita assim como a escrita é da oralidade, de forma que linguagem oral e linguagem escrita são duas práticas culturais que, reciprocamente, se interpenetram, se influenciam e se modificam.

Isso posto, no próximo tópico apresentamos os fundamentos metodológicos da pesquisa $A$ formação da atitude autora e leitora da criança no processo de apropriação da escrita.

\section{Fundamentos metodológicos da pesquisa: caminhos e procedimentos}

A referida pesquisa, em andamento, é um estudo qualitativo, de caráter etnográfico, voltada para as situações de interações verbais entre as crianças e a pesquisadora. A escolha da pesquisa qualitativa se justifica porque "trabalha com o universo de significados, motivos, crenças, valores e atitudes, o que corresponde a um espaço mais profundo das relações, dos processos e dos fenômenos" (MINAYO, 1994, p. 21).

Quanto ao caráter etnográfico, na pesquisa observamos, registramos, videografamos as crianças em contexto, isto é, "um espaço e um tempo cultural e historicamente situado, um aqui e agora específico" (GRAUE; WALSH, 2003, p. 25). Particularmente, estudamos as relações das crianças com a escrita em suas atividades cotidianas, na sala, no pátio, no refeitório, nos corredores etc., quando chegam, quando vão, enfim, em diferentes tempos que permanecem em atividade na escola.

Assim, focalizamos o processo de pesquisa no objeto em movimento - a formação da atitude autora e leitora da criança -, coerentemente com a perspectiva teórica deste estudo, principalmente com os fundamentos da Escola de Vygotsky. Na perspectiva histórico-cultural, o desenvolvimento infantil é abordado como um processo que se realiza por meio de atividades socialmente desenvolvidas, de atividades de criação significativa e simbólica, em que são produzidos os sentidos humanos, mediados pela linguagem. De acordo com Vygotsky (2000), as atividades psíquicas das crianças aparecem em cena primeiramente nas atividades sociais que participam e, depois, como atividade interna, mental. Nessa relação dialética entre atividade interpsíquica e intrapsíquica, as crianças se apropriam dos conhecimentos para seu desenvolvimento. Portanto, a formação da atitude autora e leitora da criança, no processo 
de apropriação da escrita, é o resultado de uma atividade efetiva desenvolvida em relação aos objetos e fenômenos e precisa ser mediada por alguém mais experiente que deve instruir as crianças nas formas mais elaboradas da cultura escrita.

Entretanto, para assimilar os objetos materiais e intelectuais, as crianças precisam desenvolver atividades com eles de forma que os traços essenciais da atividade estejam encarnados nesses objetos. À vista disso, entendemos que as crianças formam a atitude autora e leitora ao apropriarem-se da escrita quando participam de atividades significativas que as colocam em relação com esse objeto social, em seus usos e funções.

Nessa perspectiva, a pesquisa vem sendo realizada a partir de 2016 por meio dos seguintes procedimentos metodológicos: observações, entrevistas e experimentos pedagógicos.

Para Macedo (2006, p. 91), "o processo de observação não é um ato mecânico [...] ele está inserido num processo de interação e de atribuição de sentidos". A opção pela observação naturalista deve-se ao fato que ela "é feita no ambiente natural, como diz seu próprio nome, e não procura manipular, modificar ou mesmo limitar o meio ou os comportamentos dos participantes" (VIANNA, 2007, p. 48). Nesse sentido, esse tipo de observação tem sido produtivo para a estruturação dos experimentos pedagógicos que fazem parte da pesquisa, colaborando para compreendermos as situações contingenciais, que podem escapar do nosso controle, só perceptíveis em pesquisas de caráter etnográfico que capturam as observações casuais. Para realização das observações utilizamos como recurso a filmagem em vídeo porque nos permite rever os registros de gravação e detalhes que possibilitam realizar microanálises, principalmente das observações e entrevistas.

As entrevistas com as crianças de educação infantil e anos iniciais do ensino fundamental foram realizadas como diálogos informais no ambiente natural, em situações do cotidiano das crianças na escola. A entrevista com crian- ças tem características próprias que precisam ser consideradas, desde a aproximação com as crianças de maneira que elas possam entender do que se trata, e assim conquistar a confiança delas, respeitando os tempos possíveis para esses momentos e preferencialmente serem realizadas em grupos pequenos (GRAUE; WALSH, 2003). As entrevistas também foram gravadas em vídeo, com a câmera armada no tripé num canto mais distante da sala, para não distrair as crianças.

Sobre a metodologia experimental, de acordo com os fundamentos vigotskianos, é uma alternativa de pesquisa que contempla as relações entre planejar e desenvolver a atividade planejada por meio de ações e operações, recursos utilizados, criação das necessidades e motivos das crianças, significados e sentidos atribuídos ao objeto escrita, apreendidos no processo em sua totalidade. Por isso a opção pelo experimento pedagógico, que constitui uma metodologia com foco na relação entre os sujeitos da pesquisa - as crianças e a pesquisadora - que esclarece a relação processual de apropriação da escrita pelas crianças. A escolha do experimento pedagógico deve-se também ao fato de se basear no método histórico-genético, cujo foco está no processo ao "estudar a passagem da influência social, exterior ao indivíduo, à influência social interior ao indivíduo, buscando esclarecer os momentos mais importantes que integram esse momento de transição" (VYGOTSKY, 2000, p. 87).

Mukhina (1996) mostra que o objetivo do experimento pedagógico é mostrar a eficácia de programas e métodos de ensino, portanto o pesquisador busca alcançar bons resultados no ensino. 0 experimento pedagógico possibilita mostrar como se desenvolve esse processo da criança ao se apropriar da escrita. De acordo com Nascimento (2010), as vantagens do experimento pedagógico estão em criar uma situação especial e organizar uma intervenção para atender as finalidades da pesquisa. Serão desenvolvidos quatro experimentos pedagógicos, tendo quatro atividades cada um, num total 
de 16 atividades, de até 40 minutos de duração.

Para registrar as atividades da pesquisa, escolhemos a videografia que, segundo Meira (1994), é um recurso de registro em vídeo da atividade humana que deve ser organizado em três fases: assistir à filmagem sem interrupção; fazer anotações sobre a problemática do estudo e produzir um índice de eventos para listar e localizar facilmente os mais significativos da pesquisa; e, finalmente, transcrever os mais significativos para a análise dos dados.

Em relação à análise de dados, será feita por meio de categorias que explicitem as relações entre crianças e pesquisadora no cotidiano pesquisado, buscando diferenciar o fato real do fato científico, pois, de acordo com Vygotsky (2004, p. 234), "O fato real e o fato científico distinguem-se precisamente um do outro pelo fato de que este último constitui o fato real reconhecido em determinado sistema, isto é, uma abstração de certos traços da inesgotável soma de signos do fato natural". Trata-se de chegar ao concreto pensado, portanto é uma análise interpretativa dos dados, sendo que outras serão incorporadas no desenvolvimento da pesquisa. 0 caminho da análise dos dados inicia pela descrição das ações para identificar a atitude autora e leitora das crianças participantes no desenvolvimento do estudo, retomando essas ações sempre que necessário para verificar como influenciaram na formação da atitude autora e leitora das crianças, e, finalmente, levantar as dificuldades e os possíveis equívocos para superação das próprias limitações do estudo. Para operacionalizar os dados, buscamos Moura (2004), que define os episódios em um conjunto não linear de ações que se constituem de gestos, ações, falas reveladoras de cenas que apontam certa interdependência entre elementos de uma ação formadora.

Para realização da pesquisa, apoiamo-nos em fundamentos teóricos que dão sustentação ao estudo. No próximo tópico discutiremos esses fundamentos focando particularmente a linguagem como objeto social e, simultaneamente, instrumento cultural.

\section{Diferentes olhares para a linguagem oral e escrita}

Atualmente, a criança interage desde pequena com a linguagem oral e a escrita - uma influenciando a outra, modificando-a, embora tenham naturezas e funções diferentes. A fala é aprendida naturalmente pela criança ouvindo e participando as interações verbais com os familiares num primeiro momento, ampliando esse círculo gradualmente aos vizinhos e amigos da família e à escola de Educação Infantil.

Para Chartier, Clesse e Hébrard (1996), a criança, desde muito pequena, entra em contato e interage com a cultura escrita, inicialmente, com os gestos sociais de leitura dos familiares e os escritos presentes em casa aos quais ela tem acesso. A atribuição de significados depende da intimidade que a criança cria com esses registros escritos nas situações que vivencia, mediadas por alguém mais experiente que significa esses escritos para ela. Por isso, o entorno da criança tem um papel importante em seu processo de imersão na cultura escrita.

Em razão disso, o entorno em que vive a criança na infância desempenha um papel fundamental na apropriação das práticas de leitura e de escrita, antes da sua alfabetização propriamente dita. De acordo com Vygotsky (2010, p. 682), o meio não deve ser visto "como uma circunstância do desenvolvimento, por encerrar em si certas qualidades ou determinadas características que já propiciam, por si próprias, o desenvolvimento da criança"; faz-se necessário compreendê-lo "a partir da perspectiva de qual relação existe entre a criança e o meio em dada etapa do desenvolvimento".

Nos primeiros anos de vida da criança, a família é responsável pelas suas interações com os objetos e as pessoas que a cercam. Já na primeira infância, ela vivencia situações em que a escrita se faz presente no cotidiano por meio dos portadores de texto como listas de mercado, revistas, celular, televisão, tablets, computadores, calendários e outros escritos que frequentemente se fazem presentes na vida 
familiar. Assim, inicia seu contato com a escrita em múltiplos gêneros textuais que implicam diferentes usos em contextos específicos. A escrita é, portanto, um objeto social que circula nas relações sociais, de maneira que sua apropriação requer situações significativas e pressupõe contextos ricos nos quais esse objeto social está inserido na vida cotidiana.

Não faltam modelos teóricos que expliquem como a escrita é assimilada pela criança, que expõem detalhadamente esse processo. Ferreiro e Teberosky (1999) mostram que precisamos estudar a natureza dos processos de assimilação de conhecimentos sobre a escrita para compreendermos como a criança aprende a escrever. Os estudos comportamentais definem a aprendizagem da escrita pelo binômio estímulo-reação, os cognitivistas a conceituam como um processo de relação do sujeito com o meio que possibilita à criança organizar as informações novas às estruturas cognitivas. Piaget (1978) concebe esse processo como resultado do equilíbrio entre acomodação e assimilação no desenvolvimento intelectual da criança.

Há mais de três décadas, Magda Soares (1983) já destacava em um estudo sobre a questão da alfabetização brasileira, $A$ aprendizagem da língua materna: problemas e perspectivas, a ausência de uma reflexão teórica sobre como as crianças aprendem a língua materna, intencional e sistematicamente, e sobre a necessidade de uma prática pedagógica adequada para dar conta desses processos. Um seminário organizado pelo INEP-MEC, de acordo com Soares (1983, p. 13), já naquele momento, indicava uma série de pesquisas necessárias, entre elas, "pesquisas que permitam delinear melhor os objetivos e a prática educacionais a serem desenvolvidos na pré-escola, no que diz respeito às habilidades linguísticas básicas necessárias para um bom desempenho escolar e social".

Optamos neste artigo por analisar os gestos de escrita de Ivo, um menino de seis anos, que frequentava o primeiro ano do Ensino Fundamental, participante de uma das entrevistas realizadas como parte do projeto de pesquisa institucional em andamento denominado $A$ formação da atitude autora e leitora no processo de apropriação da escrita na educação infantil na perspectiva histórico-cultural.

Para analisar os dados levantados, buscamos os aportes teóricos em Vygotsky e Luria e, também, na teoria da enunciação de Bakhtin. Autores contemporâneos, estrangeiros e brasileiros complementam a abordagem do processo de apropriação da escrita como um processo de significação social.

\section{0 processo de apropriação da escrita: como as crianças aprendem a escrever}

É pela experiência social que a criança assimila a cultura escrita, em ações externas e, simultaneamente, em ações internas que lhe permitem significar a escrita e desenvolver funções psíquicas superiores como a atenção voluntária, o pensamento abstrato, a memória, a imaginação. As ações realizadas pela sua atividade-guia dependem de suas condições de vida e de educação.

Leontiev (1983) mostra em seus primeiros trabalhos que Vygotsky conceitua atividade como princípio explicativo da consciência, ou seja, a consciência da criança se constrói de fora para dentro, nas atividades que participa com o outro, portanto atividades sociais. Esclarece ainda Vygotsky, de acordo com Luria (1988), que a criança passa da consciência social para a consciência individual mediada pela linguagem, isto é, pelos signos. A linguagem, seja ela oral ou escrita, é um instrumento mediador semiótico por excelência. Nesse sentido, a cultura escrita como conhecimento produzido na atividade humana precisa ser apropriada pela criança. Todavia, os conhecimentos, especificamente da cultura escrita, não estão materializados nos objetos, por isso precisam ser mediados por alguém mais experiente. 
Leontiev (2004, p. 290) elucida que:

As aquisições do desenvolvimento histórico das aptidões humanas não são simplesmente dadas aos homens nos fenômenos objetivos da cultura material e espiritual que os encarnam, mas são aí apenas postas. Para se apropriar destes resultados, para fazer deles as suas aptidões, 'os órgãos da sua individualidade', a criança, o ser humano, deve entrar em relação com os fenômenos do mundo circundante através doutros homens, isto é, num processo de comunicação com eles. Assim, a criança aprende a atividade adequada. Pela sua função, este processo é, portanto, um processo de educação.

A atividade pedagógica não pode, nesse sentido, apartar-se das condições reais necessárias ao desenvolvimento da criança. Diante disso, a educação escolar, no que tange à aprendizagem da escrita, precisa considerar que:

[...] a criança aprende a ler, na escola, a escrever, a fazer contas, quando aprende os fundamentos da ciência, assimila uma experiência humanosocial, da qual não poderia assimilar nem sequer uma milionésima parte se seu desenvolvimento fosse apenas determinado pela experiência que pode alcançar-se mediante uma interação direta do ambiente. (LURIA, 2005, p. 110).

Para não desenvolver uma atividade alienada e alienante, é preciso que o professor planeje as atividades com a escrita, considerando a necessidade de a criança se apropriar da cultura escrita, bem como o motivo que pode impulsioná-la a alcançar o objetivo inicialmente proposto para a realização da atividade. Uma atividade significativa sobre a escrita supõe os elementos: desejo, necessidades, emoções, tarefas e ações, e os motivos, meios e planos para as ações.

A família tem, também, um papel preponderante para a apropriação da cultura escrita construída pelas gerações precedentes. No processo de apropriação da escrita pela criança é preciso que essa necessidade cultural seja criada como uma necessidade sua, isto é, a necessidade de utilizar a escrita em toda a sua funcionalidade social para constituir-se autora de sua escrita. Diferentemente da atividade escolar, a atividade no cotidiano é informal, mas extremamente importante para o mergulho da criança na cultura escrita.

Para que a criança se aproprie da cultura escrita, as atividades na Educação Infantil e nos anos iniciais do Ensino Fundamental precisam ser planejadas intencionalmente de forma a impulsionar o desenvolvimento infantil, ou seja, a formação de suas funções psicológicas superiores, isto é, de sua personalidade, ou seja, a atividade com a escrita na educação escolar implica pensar no tripé ensino-aprendizagem-desenvolvimento.

Identificar os sentidos que a criança atribui à escrita e as implicações diretas que tais sentidos exercem sobre o processo de apropriação desse objeto é condição sine qua non para compreender como ela se relaciona com a escrita no processo de sua apropriação e como se desenvolve.

Diferentemente da fala, a aprendizagem da leitura e da escrita demanda ensino e, consequentemente, o professor como organizador do trabalho educativo para planejar atividades significativas de escrita como língua viva, em seus usos e funções. Isso implica em criar as condições de ensino para a criança constituir-se como sujeito autor num contexto social mais amplo da sociedade como fonte de conhecimento historicamente acumulado pela humanidade. A aprendizagem da escrita é, nesse sentido, uma atividade coletiva que supõe as interações sociais entre crianças e adultos (FOUCAMBERT, 1994).

De acordo com Luria (1988) e Vygotsky (2000, 2001), os processos que se constituem na criança, durante a fase inicial de alfabetização, resultam das relações com outras pessoas - crianças e adultos - que lhes ensine a escrita em sua complexidade. Para aprender a escrever, de acordo com Vygotsky (2001), a criança realiza atividades externas, em nível interpsíquico, e atividades internas, em nível intrapsíquico. Do ponto de vista pedagógico, isso significa a capacidade de usar a escrita para si como para os outros. Essa capacidade não se desenvolve de forma espontânea e na- 
tural, precisa ser planejada e ensinada intencionalmente pelo professor.

Vygotsky (2000) mostra que, inicialmente, o gesto inicial do bebê e o desenho e a brincadeira de papeis sociais da criança ganham significados e transformam-se em signos independentes, uma vez que para a apropriação da escrita é necessário o gesto que lhes confira significado e função. Assim, o desenvolvimento da escrita tem um longo caminho até chegar à aquisição da escrita simbólica; nesse percurso a criança vai formando a função simbólica, necessária ao seu desenvolvimento e à formação de sua consciência. À vista disso, a criança representa uma ideia desenhando, de maneira que a pictografia constitui um instrumento semiótico para ela chegar à escrita simbólica, assim como a brincadeira vai ganhando significado pelo que significa para a criança em relação ao sistema de vida dos adultos.

Nessa perspectiva, dominar a linguagem escrita para a criança é dominar um sistema complexo de signos simbólicos:

[...] O domínio deste sistema complexo não pode realizar-se por uma via exclusivamente mecânica, desde fora, por meio de uma simples pronunciação, de uma aprendizagem artificial. [...] 0 domínio da linguagem escrita é, na realidade, o resultado de um largo desenvolvimento das funções psíquicas superiores do comportamento infantil. [...] O desenvolvimento da linguagem escrita não segue uma linha única, nem conserva nada parecido a uma sucessão de formas. Na história do desenvolvimento da linguagem escrita na criança nos encontramos com as metamorfoses mais inesperadas, quer dizer, com a transformação de umas formas de linguagem escrita em outras. (VYGOTSKY, 2000, p.184, tradução nossa).

Para explicar o processo de apropriação da escrita, Luria (1988, p. 144) vai às origens desse processo, no período pré-escolar, evidenciando que a criança tem uma pré-história da escrita, ao esclarecer que:

[...] já tinha desenvolvido por si mesma um certo número de técnicas primitivas, semelhantes àquilo que chamamos escrita e capazes de, até mesmo, desempenhar funções semelhantes, mas que são perdidas assim que a escola proporciona à criança um sistema de signos padronizados $\mathrm{e}$ econômico, culturalmente elaborado. Estas técnicas primitivas, porém, serviram como estágios necessários ao longo do caminho.

Quando o professor conhece as técnicas primitivas de escrita da criança, passa a compreender as relações dela com a cultura escrita, antes de ingressar na escola, uma vez que a escrita é uma criação cultural presente no meio social em que ela vive, desde seu nascimento. Conhecer a pré-história de escrita da criança é necessário para o professor considerar em seu planejamento os conhecimentos empíricos que a criança tem sobre esse objeto. Além disso, é importante também que o professor tenha uma concepção da escrita da criança.

Luria (1988, p. 146) define a escrita como "uma técnica auxiliar usada para fins psicológicos; a escrita constitui o uso funcional de linhas, pontos e outros signos para recordar e transmitir ideias e conceitos".

No início, a criança estabelece uma relação funcional com a escrita, ou seja, compreende sua funcionalidade social empregando signos auxiliares como linhas, letras, pontos, entre outros, para registrar uma ideia e, depois, recordar o escrito.

No processo de apropriação da escrita pela criança é preciso que essa necessidade cultural seja criada, isto é, a necessidade de utilizar a escrita em toda a sua funcionalidade social e usos. Isso exige a organização de atividades que propiciem o desenvolvimento de suas funções psíquicas superiores, ao tomarmos como ponto de partida suas necessidades em cada etapa do desenvolvimento, atentando para o fato que as necessidades da criança vão se transformando ao longo de sua história de desenvolvimento, ou seja, de sua ontogênese. Nesse processo, modificam-se os motivos que a impulsionam para a ação com os objetos, entre eles a escrita. É sobre essa base psicológica da criança que se concretizam as mudanças em sua atividade-guia, seja ela a brincadeira ou o 
estudo, consequentemente, a passagem de um estágio de desenvolvimento a outro.

Refletir sobre o processo de apropriação da escrita, tendo em vista a superação da aprendizagem mecânica de traçar letras, implica desde sua origem a elaboração de significados e sentidos pela criança que passam pela sua atividade externa e interna. Esse processo supõe atividades com a escrita que sejam significativas para impulsionar o desenvolvimento da criança, desde a atividade objetal na primeira infância, o desenho e as brincadeiras de papeis sociais, as garatujas, até a escrita simbólica.

Ressaltamos a essencialidade de uma abordagem teórica que possibilite ao professor compreender que não é a aprendizagem do código alfabético que permite à criança apropriar-se da escrita, mas é sua formação autora que cria necessidades para a apropriação da escrita em seus usos e funções, sendo a aprendizagem da técnica da escrita apenas uma parte desse processo. Portanto, podemos sustentar a ideia que apropriar-se da escrita é constituir-se sujeito autor desse objeto sociocultural.

Se na escola, como temos constatado em estudos publicados, a concepção de escrita é associada a uma prática alienante e alienadora e sua apropriação resulta em atos fragmentados que se circunscrevem ao traçado das letras e sua correspondência sonora, esvaziada de significado, desconectada da realidade, carece inverter essa situação focando a problemática com diferentes aportes teóricos e métodos que considerem a relevância da significação social desse processo.

Os estudos de Bakhtin sobre a linguagem trazem também uma relevante contribuição para compreendermos a significação social na apropriação da escrita. Segundo Bakhtin (1992, p. 35), a palavra é "um fato socioideológico", pois se forma no meio ideológico e social em que se dão as relações sociais. Nesse processo, linguagem (signos) e consciência se desenvolvem simultaneamente nas relações sociais das quais participamos, isto é, na relação com o outro, pois a palavra é sempre dirigida para alguém, um interlocutor. Assim, a palavra vem de alguém e se dirige para alguém, logo como signo verbal só se realiza nas relações sociais, nas interações entre indivíduos. A palavra como signo verbal existe nas relações sociais, nas interações verbais entre indivíduos e, para esse autor, só no processo de enunciação pode ser encontrada.

A atividade humana sempre se relaciona com a utilização da língua e sua variação concretiza-se por meio de enunciados concretos e únicos - orais e escritos - produzidos por sujeitos em condições específicas e com finalidades diversas. Essa variação da língua no processo de enunciação se dá quanto ao conteúdo temático, ao estilo verbal e, principalmente, pela sua estrutura composicional. Esses três elementos no enunciado caracterizam a especificidade de uma esfera da comunicação, tal é a heterogeneidade da comunicação verbal marcada pelos gêneros do discurso.

Segundo Bakhtin (1992, p. 279):

Qualquer enunciado considerado isoladamente é, claro, individual, mas cada esfera de utilização da língua elabora seus tipos relativamente estáveis de enunciados, sendo isso que denominamos gêneros do discurso. A riqueza e a variedade virtual da atividade humana é inesgotável, e cada esfera dessa atividade comporta um repertório de gêneros do discurso que vai diferenciando-se e ampliando-se à medida que a própria esfera se desenvolve e fica mais complexa.

As atividades com a linguagem, oral e escrita, na perspectiva bakhtiniana, pressupõem uma relação dialógica, isto é, uma interação dos indivíduos com a escrita em sua diversidade de gêneros textuais, suportes e situações de uso, com o outro e consigo mesmos, considerando que a palavra é por sua natureza também dialógica, ou seja, a palavra como fato socioideológico traz em si as marcas da dialogicidade.

$\mathrm{Na}$ perspectiva dialógica, a escrita como objeto de ensino implica a mediação pedagógica, ou seja, a mediação do professor ao abordar a escrita em sua dinamicidade e movimento, pois, para Bakhtin (1992), a vida é por natureza dialógica - o homem é concebido nas relações com o 
outro - e essa relação funda a linguagem, atribuilhe sentido, e constrói sujeitos produtores de enunciados. Essa é uma questão fundamental no processo de apropriação da linguagem escrita: a dialogicidade da vida e da linguagem.

De acordo com Dolz, Pasquier e Bronckart (1993 apud SCHNEUWLY; DOLZ, 2004, p. 63), "uma ação de linguagem consiste em produzir, compreender, interpretar e/ou memorizar um conjunto organizado de enunciados orais ou escritos (um texto no sentido geral que damos a esse termo como unidade linguística)". Em diferentes contextos e suportes e múltiplos gêneros textuais, o texto deve constituir o objeto da aprendizagem da escrita na escola.

Bajard (2012, p. 13) afirma que "se a escrita é uma linguagem, podemos encontrar um modelo metodológico dentro da pedagogia da aprendizagem das línguas". Para esse autor, à criança precisa ser garantida as amostras múltiplas de linguagem escrita, e, acrescentaríamos, as formas ideais escritas em suas máximas qualidades para que as explore apropriando os significados e lhes atribuindo sentidos. Para Bajard (2012, p. 13),

Não é a partir de um código reduzido ensinado pelo adulto que a criança adquire uma língua (oral ou escrita), mas sim a partir das regularidades em vigor das amostras de linguagem que ela retira elementos novos a serem agregados ao seu saber linguístico já constituído.

Arena, Arena e Santos (2011) analisam a escrita de uma criança de seis anos de idade que frequenta uma escola do interior do estado de São Paulo, numa atividade de correspondência escrita com outra criança de São Luís, no Maranhão. Uma das hipóteses testadas pelos pesquisadores, de que a letra porta traços de significado da palavra em um enunciado no contexto de escrita de uma carta, evidencia que a letra, a palavra e o enunciado adquirem funções plurais no processo de apropriação da escrita, bem diferente de situações em que a escrita é apresentada às crianças como uma simples técnica que reduz a letra à correspondência convencional grafema/fonema.
Mello e Farias (2010, p. 53), ao discutirem os resultados de um estudo com crianças de cinco anos em uma escola pública no interior paulista, indicam "os saltos de qualidade na objetivação das crianças em direção às formas mais elaboradas a que passaram a ter acesso, demonstrando a apropriação que realizaram, tendo a cultura elaborada como fonte de sua humanização". A discussão feita pelos autores centra-se na questão do sentido da escrita produzido pelas crianças em situações por elas vivenciadas.

Ao mostrar os resultados de avaliações nacionais e internacionais que revelam problemas com o ensino da linguagem escrita, Mello e Farias (2010) apontam que esses resultados, ainda que relativos, são uma denúncia dos problemas que enfrentamos com a aquisição da linguagem escrita pelas crianças. A questão primordial na educação escolar é o sentido que as crianças aprendem a atribuir à linguagem escrita no processo de formação da atitude autora e leitora.

Souza (2015) aponta que o conhecimento espontâneo que as crianças trazem para a escola precisa ser valorizado como ponto de partida para o professor trabalhar as formas mais elaboradas de escrita. Essa autora analisa o processo de apropriação da leitura e da escrita de crianças de cinco e seis anos, por meio de gêneros textuais no contexto das técnicas Freinet, evidenciando que a criança estabelece relações com a leitura e a escrita por meio dos gêneros textuais, em situações de ensino em que a língua não é dada como produto final, mas precisa ser elaborada e reelaborada por meio da construção de textos em seu processo.

Silva e Alves (2015) mencionam o papel relevante da aquisição da escrita no desenvolvimento infantil, ao possibilitar o domínio de maneiras complexas de pensar e de agir, condição para a inserção da criança como sujeito autônomo na sociedade. Argumentam essas autoras, fundamentadas na teoria históricocultural, que um dos propósitos da escola é criar condições para que as crianças se desen- 
volvam plenamente ao se apropriarem de instrumentos e signos historicamente construídos pela humanidade.

Smolka (2012) escreve na nota à 13 a edição de seu livro A criança na fase inicial da escrita, retomando um estudo realizado na década de 1980, uma retrospectiva sobre a problemática da aprendizagem inicial da escrita. A primeira constatação dessa autora é que o número de pesquisadores e grupos de pesquisa multiplicou nessas décadas, o que se reflete na vasta produção acadêmica. Houve uma mudança perceptível nessas pesquisas: os estudos centraram-se em métodos de ensino e processos de aprendizagem; alargaram-se para a história da alfabetização, da leitura e da escrita, das práticas de letramento.

De acordo com essa autora, a partir da década de 1980 ganham destaque as múltiplas facetas da questão da alfabetização e dos estudos de Emilia Ferreiro sobre como as crianças desenvolvem a escrita. Os debates sobre os estudos de Piaget e Vygotsky parecem ter se diluído à medida que as pesquisas de Ferreiro foram incorporadas pelos professores com foco nas hipóteses levantadas pelas crianças em seu processo inicial de aprendizagem da escrita. Na reflexão que faz, Smolka (2012, p. 14) sinaliza que são visíveis as mudanças quanto às condições, aos instrumentos, às práticas e prescrições, mas persistem "os gestos de ensinar" que "podem suscitar debates e mobilizar controvérsias sobre as relações de ensino e os muitos modos de alfabetizar". Acreditamos que a questão continua crucial e implica que professores e pesquisadores respondam a pergunta: para que alfabetizamos?

\section{Significar ou decifrar: contradições no processo de alfabetização de Ivo}

Os métodos de alfabetização comumente usados nas escolas partem do princípio de que é necessário propor à criança tarefas que desenvolvam e treinem habilidades perceptivas (auditivas, visuais e motoras). Ao considerar que o desenvolvimento dessas habilidades é um requisito para a aprendizagem da linguagem escrita, pressupõe-se que o desenvolvimento de tais habilidades pode favorecer a aprendizagem da escrita em sua complexidade. Desconsidera-se, nessa perspectiva, que para aprender a escrever é necessário a interação da criança com o outro em atividades com a língua viva, em seu processo de enunciação, de forma que ela possa apropriar-se dos significados como fenômeno do pensamento e da linguagem e tornar seus esses conhecimentos, historicamente construídos pelos homens.

Neste artigo abordamos um episódio da pesquisa: a entrevista com Ivo; e realizamos uma microanálise desse episódio no contexto da pesquisa ainda em andamento. 0 dado foi coletado em abril de 2016, por meio de um diálogo informal com Ivo, aluno do primeiro ano do ensino fundamental de uma escola situada no interior do estado de Minas Gerais, no Triângulo Mineiro. 0 episódio analisado faz parte de um conjunto de entrevistas que foram realizadas como procedimento metodológico para compreender como as crianças se apropriam da escrita.

Ivo é um menino alegre, aparentemente tímido, bastante conversador. Estava sendo alfabetizado. Quando o entrevistamos, ele estava acompanhado de sua avó, uma professora que participara de um projeto de extensão sobre o papel da linguagem no desenvolvimento da criança.

Aproximamo-nos dele, perguntando-lhe seu nome, sua idade, o nome de sua escola. No começo, Ivo respondia às perguntas com poucas palavras. Quando indagamos se estava aprendendo a escrever, mostrou-se visivelmente interessado na conversa. Ao perceber seu desejo de escrever alguma coisa, pedimos que escrevesse em uma folha de papel sulfite. Ele não hesitou em registrar a palavra $H U L K$, para em seguida revelar os sentidos atribuídos a esse gesto da escrita. 
0 primeiro gesto de escrita de Ivo, na folha em branco, sem titubear, foi o registro da palavra $H U L K$, em caixa alta, como a palavra é grafada em inglês. Logo a seguir, ele leu sem ser solicitado e lhe perguntamos o que significava essa palavra. Ivo desandou a falar, demonstrando que para ele a palavra tinha um significado e ele lhe atribuíra um sentido pessoal.

Figura 1 - Primeiro gesto de escrita de Ivo

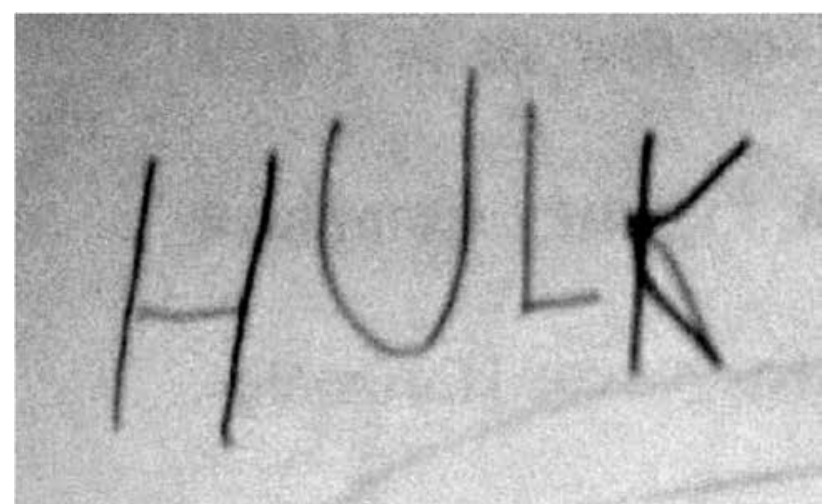

Fonte: Acervo pessoal das autoras.

A fala de Ivo revelara os sentidos que ele atribuíra, descrevendo minuciosamente a personagem e seus poderes, com a qual ele parecia conviver intensamente nos filmes que assistia pela televisão. A vó, que escutava em silêncio, apenas confirmava com um aceno afirmativo de cabeça. Mais tarde nos contou que o neto assistia aos filmes, via quadrinhos sobre a personagem etc., e Hulk era um de seus heróis.

No final desse diálogo, Ivo falou em voz baixa que queria ser como Hulk quando crescesse. Ouvindo-o, compreendemos que a palavra HULK tinha para ele sentidos construídos em cada encontro com a personagem, nas histórias em quadrinhos e filmes tão amplamente divulgados no país. Parecia já representar um simbolismo de primeira ordem e sua escrita vinha acompanhada de um desejo intenso de escrever, aprender a escrever e dominar a escrita. A palavra HULK ganhara um sentido único a partir de suas vivências e sua subjetividade. $\mathrm{Na}$ fala de Ivo, a palavra tornara-se um texto repleto de significado e sentido.

HULK para Ivo é um signo verbal, e como fato socioideológico tem para ele um sentido pessoal que ele comunicava naquele diálogo às pesquisadoras (BAKHTIN, 1992). A atribuição de sentido no processo de apropriação da escrita pela criança só se realiza nas interações sociais, pois é no processo de interlocução que o significado e o sentido são estabelecidos. Para além de palavras, escrevemos pensamentos, sentimentos, valores, o que explica o primeiro gesto da escrita de Ivo: a palavra HULK tem significação social e ele lhe atribui um sentido ao dela se apropriar: um ser poderoso que tem uma história com a qual ele se identifica.

A decodificação do código escrito não forma o escritor que atribui sentido ao que comunica e expressa, uma vez que envolve um fazer desconectado de significado e ações infantis destituídas de sentido. Conforme assinala Vygotsky (2000), as aprendizagens decorrentes dessas ações - traçar as palavras, sem saber produzir textos e atribuir sentido à escrita - não têm força motora sobre o pleno desenvolvimento da inteligência e personalidade da criança.

Em síntese, ao conceber e embasar as ações pedagógicas na perspectiva de que a escrita assume um papel essencial no desenvolvimento cultural de cada sujeito, é preciso considerar, como Vygotsky (2000), que a aprendizagem da escrita é um processo sofisticado em que o sujeito aprende a dominar um sistema complexo de símbolos. Participam desse processo, de um lado, a criança como sujeito ativo, de outro, o professor como mediador e criador de mediações, isto é, como escriba e leitor.

À vista disso, poderíamos dizer que não é a aprendizagem do código alfabético que permite a criança apropriar-se da escrita, mas é na atividade de ler e escrever como sujeito dos atos de leitura e de escrita que ela cria a necessidade de apropriar-se da escrita em seus usos e funções. A aprendizagem da técnica da escrita é apenas uma parte do processo. Em vista disso, entendemos que alfabetizar é ensinar os atos de leitura e de escrita que possibilitem à criança o mergulho na cultura escrita, sendo a técnica da escrita uma ferramenta nesse processo, portanto um meio e não um fim em si mesma. 
Inferimos então que ensinar os atos de leitura e de escrita no processo de apropriação da escrita pela criança implica em alfabetizá-la com textos. A palavra como parte do todo - o texto - é a unidade mínima de significação.

0 segundo gesto de sua escrita, também em caixa alta, foi o registro das letras A MECANM $O$. Pedimos que lesse, ele suspirou e disse que não sabia ainda ler. Perguntamos o que queria dizer aquele registro escrito. A resposta foi um olhar interrogativo. Percebemos sua inquietude.
As letras ali dispostas pareciam nada significar para Ivo. Não era uma palavra, não eram signos, portanto eram apenas sinais gráficos registrados, vazios de significado, sem nenhuma função, assim dispersos, na tentativa de mostrar que ele estava aprendendo as letras. Era o que estava aprendendo na escola: memorizar e grafar letras que um dia haveria de juntar e escrever palavras com significado e, quem sabe, então, descobrisse a escrita em seus usos e funções.

Figura 2 - Segundo gesto de escrita de Ivo

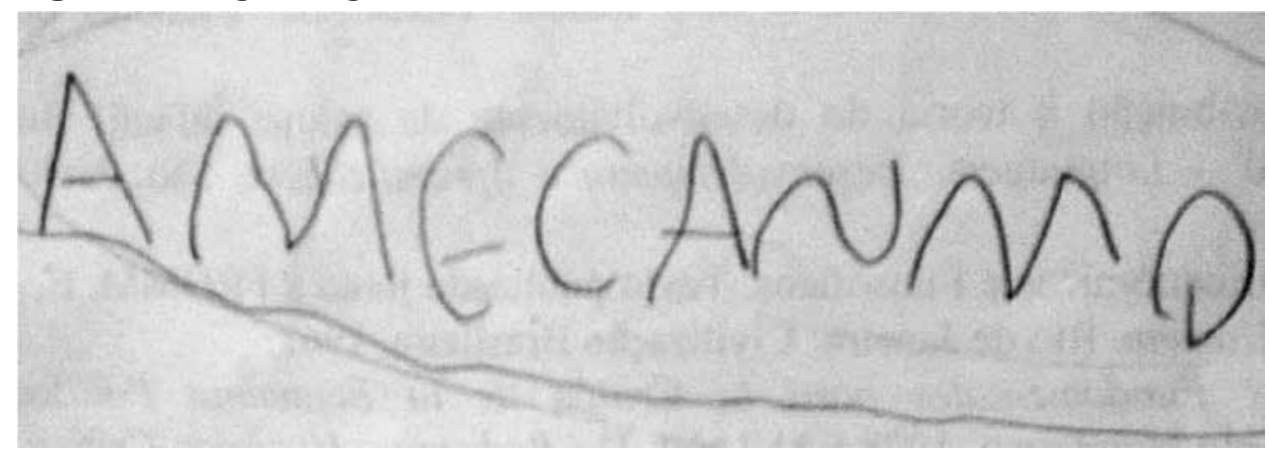

Fonte: Acervo pessoal das autoras.

Vygotsky (2001), há quase um século, já denunciava: não se ensina para a criança a linguagem escrita, ensina-se a traçar letras, sílabas e a formar palavras. Na leitura prevalece o mesmo método - a decodificação e codificação do código alfabético. 0 ensino do mecanismo da escrita e da leitura baseia-se no ensino da ortografia e da caligrafia. Essa conduta se explica historicamente, segundo esse autor, pois mesmo com os diversos métodos de ensino de leitura e escrita criados, a pedagogia não elaborou um sistema de ensino de linguagem escrita racional com fundamentos científicos e práticos.

Insatisfeito com seu segundo gesto de escrita, Ivo, sem que solicitássemos, registra no papel sulfite as letras do alfabeto: $A B C D F G H$ IJ KL MNO PQR S T UVWXYZ. Tudo em caixa alta, como está aprendendo na escola, com pequeno espaço em branco entre uma e outra, sendo que, no final, a letra " $z$ " foi registrada três vezes, com diferentes traçados.

Figura 3 - Terceiro gesto de escrita de Ivo

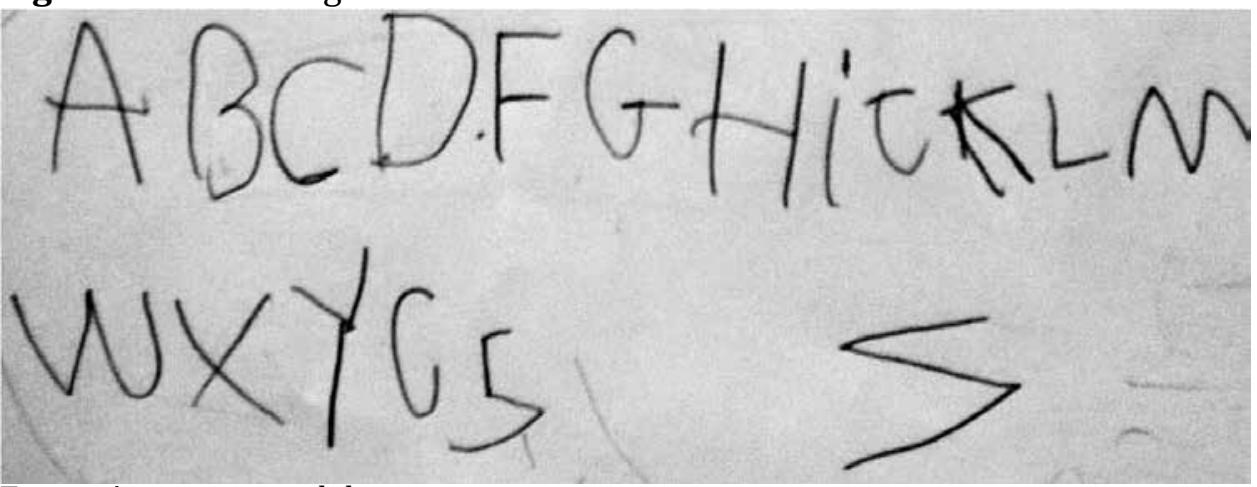

Fonte: Acervo pessoal das autoras. 
Perguntamos novamente a ele o que significava o escrito, o que queria dizer com aquele registro. Uma pausa longa, ele olha para os lados e se aproxima mais das pesquisadoras para dizer quase sussurrando: "Eu não sei dizer e acho que ninguém sabe". Dado revelador, em tom de confissão, Ivo revela que aquele conjunto de letras na ordem alfabética não fazia sentido algum para ele. Mais ainda, não devia fazer sentido para ninguém. Assim, isoladas, as letras não tinham nenhum significado.

0 episódio lembra a cartilha Caminho Suave, a lição "Ivo viu a uva", o ensino pelo método silábico que alfabetizava a criança ensinando a juntar consoantes e vogais, escrever sílabas que eram dispostas como na frase acima desprovida de significado, apenas para ensinar as sílabas va-ve-vo. Ivo, o sujeito desta pesquisa não viu a uva da cartilha Caminho Suave, mas igualmente está aprendendo que consoantes juntas a vogais, obedientemente posicionadas, militarmente perfiladas em ordem linear, formam pelotões de sílabas como o $b a$-be$b i-b o-b u$. Isso é apresentado para a criança em substituição à escrita como instrumento cultural complexo.

De acordo com Arena, Arena e Santos (2011, p. 69, grifo nosso),

Como unidade da palavra, a letra teria, na sua construção, uma função a cumprir, uma posição a ocupar, uma relação a estabelecer com as demais, em ação dinâmica. [...] a letra com função preserva a propriedade do todo, da palavra, do significado, do discurso. Se esse processo de preservação da propriedade do todo não ocorrer, a unidade deixa de ser unidade desse todo da qual faria parte constitutiva. Desse modo, a consideração da função como objeto de estudo em alfabetização poderá acionar outras discussões de natureza pedagógica a respeito do ensino isolado da letra como elemento (e não como unidade) da palavra.

A letra tomada isoladamente, como um elemento, fora de seu contexto - a palavra - não pode ter uma função, já não participa mais de uma unidade, não tem as propriedades contidas no todo, portanto é apenas um sinal, um som como qualquer outro. A aprendizagem da escrita por meio de repetições do alfabeto, de sílabas e até mesmo de palavras fora de sua significação social dificultam a apropriação da escrita pela criança. Esse é o caminho das pedras, quando poderíamos facilitar o processo de alfabetização; estamos criando obstáculos ao substituir a linguagem escrita pelo sistema alfabético da língua.

Segurando com firmeza o lápis, Ivo registrou separadamente a vogal $a$ e a vogal $e$, em seguida as três vogais unidas iou, sem espaço em branco. Deve memorizá-las e juntando as consoantes formar sílabas, depois palavras e, finalmente, textos. É assim que está aprendendo na escola. Contudo, fora da escola, a escrita para Ivo ganha outras formas, funções e disposições na folha em branco, como vimos em HULK. Na palavra por ele apropriada, a escrita ganha sentido, ganha vida, ele é o sujeito dessa escrita, mas a escola parece ignorar esse gesto.

Figura 4 - Quarto gesto de escrita de Ivo

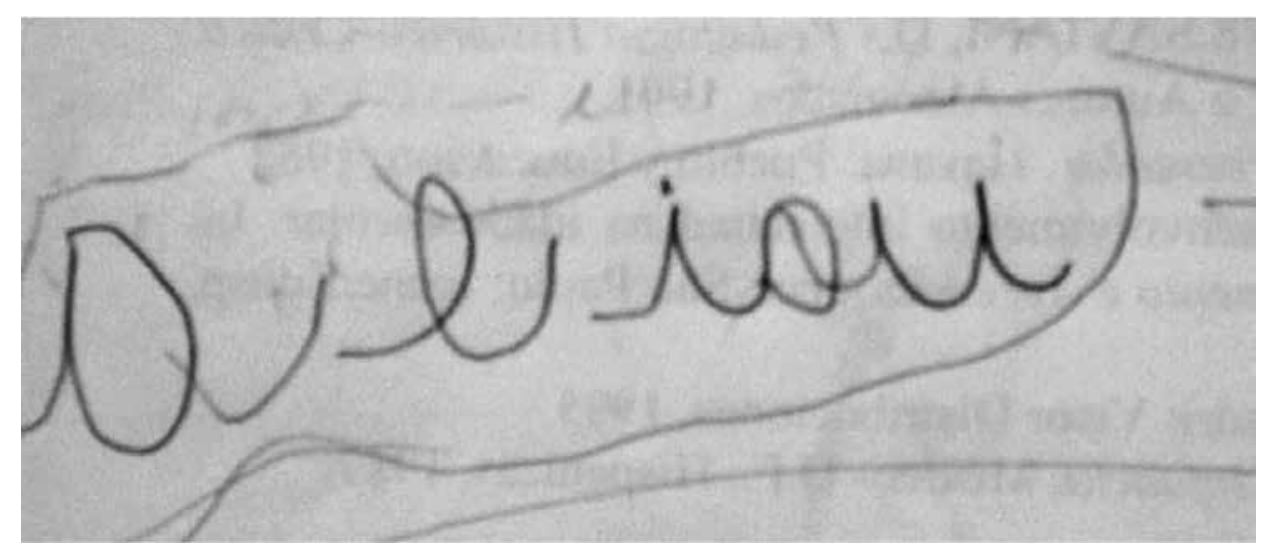

Fonte: Acervo pessoal das autoras. 
É no mundo da cultura, no processo de apropriação e objetivação, que formamos a esfera motriz, de acordo com Mello (2007). A esfera motriz como conjunto de gestos que possibilitam à criança o uso de objetos e instrumentos e, também, as funções intelectuais do processo. É assim que a criança constitui sua humanidade, as qualidades humanas que são suas habilidades, capacidades e aptidões formadas ao longo de sua história, na atividade humana. Esse processe se dá na vida, incluindo-se a vida escolar.

Para Possenti (1996, p. 48), "o modo de conseguir na escola a eficácia obtida nas casas e nas ruas é 'imitar' da forma mais próxima possível as atividades linguísticas da vida". De acordo com esse autor, aprendemos assim a falar e a ouvir. "Na escola, as práticas mais relevantes serão, portanto, escrever e ler" (POSSENTI, 1996, p. 48). Segundo Possenti (1996, p. 49), "a escola é um lugar de trabalho". Contudo, não se trata de escrever textos como exercícios eventuais para corrigir. As crianças precisam escrever "como se escreve de fato 'na vida"” (POSSENTI, 1996, p. 49).

A escola não pode apartar-se da vida, pois a escrita como objeto cultural está no cotidiano vivido pela criança, nas suas interações com o outro, nas atividades e gestos que a inserem na sociedade letrada.

\section{Algumas considerações}

0 estudo mostrou o desejo de Ivo de aprender a língua viva, mas, com exceção de seu primeiro gesto, a escrita da palavra HULK, os outros três gestos de escrita apresentam indícios de que seu processo de alfabetização na escola não criou condições adequadas para as interações verbais pelas quais ele possa efetivamente apropriar-se da escrita em sua complexidade.

Seus gestos revelam indícios que a escrita não pode ser dominada de forma mecânica, em uma aprendizagem artificial, que ignore a apropriação da escrita como o resultado de um longo processo de desenvolvimento das funções superiores do comportamento infantil. Nesse processo, dialeticamente, a criança escreve para desenvolver-se e desenvolve-se ao escrever. A aprendizagem da escrita impulsiona o desenvolvimento infantil que, por sua vez, possibilita avançar na apropriação da escrita como instrumento cultural complexo.

Ao registrar letras do alfabeto que para ele não têm função, Ivo está aprendendo que escrever é cifrar e ler é decifrar o código alfabético, apenas a técnica da escrita que mostra seus elementos externos, mas a alfabetização como técnica parece não propiciar sua inclusão na cultura escrita.

O paradoxo está estabelecido: de um lado, Ivo revela com a escrita da palavra HULK que na vida este gesto é pleno de significado e sentido; por outro lado, o segundo, terceiro e quarto gestos de escrita revelam que na escola, provavelmente, predomina o ensino de letras sem uma função, sem significado e sem sentido. Entre a aprendizagem do código alfabético na escola e a cultura escrita que descobre na vida cotidiana, Ivo vai abrindo um caminho para descobrir e significar a escrita, mas a escola, que deveria criar as condições para a alfabetização de Ivo como processo de apropriação escrita viva, muitas vezes, parece ignorar esse processo.

\section{REFERÊNCIAS}

ARENA, D. B.; ARENA, A. P. B.; SANTOS, S. O. Escolhas das letras nas primeiras escritas infantis: função e unidade no discurso. Ensino Em Re-Vista, Uberlândia, v. 18, n. 1, p. 67-80, jan./jun. 2011.

BAJARD, E. A descoberta da língua escrita. São Paulo: Cortez, 2012.

BAKHTIN, M. M. Marxismo e filosofia da linguagem. 6. ed. São Paulo: Hucitec, 1992.

CHARTIER, A. M.; CLESSE, C.; HÉBRARD, J. Ler e escrever: entrando no mundo da escrita. Porto Alegre: Artes Médicas, 1996.

FERreiro, E.; TEBERoSKY, A. Psicogênese da língua escrita. Porto Alegre: Artmed, 1999.

FOUCAMBERT, J. A leitura em questão. Porto Alegre: Artes Médicas, 1994. 
GRAUE, M. E.; WALSH, D. J. Investigação etnográficas com crianças: teorias, métodos e éticas. Lisboa: Fundação Calouste Gulbenkian, 2003.

LEONTIEV, A. N. Actividad, conciencia, personalidad. Ciudad de la Habana: Editorial Pueblo Y Educación, 1983.

0 desenvolvimento do psiquismo. 2. ed. São Paulo: Centauro, 2004.

LURIA, A. R. 0 papel da linguagem na formação de conexões temporais ea regulação do comportamento em crianças normais e oligofrênicas. In: LURIA, A. R. Et al. Psicologia e Pedagogia: bases psicológicas da aprendizagem e do desenvolvimento. São Paulo: Centauro, 2005. p. 107-125.

0 desenvolvimento da escrita na criança. In: VYGOTSKY, L. S.; LURIA, A. R.; LEONTIEV, A. N. Linguagem, desenvolvimento e aprendizagem. 5. ed. São Paulo: Ícone, 1988. p. 143-189.

MACEDO, R. S. Etnopesquisa crítica, etnopesquisa-formação. Brasília, DF: Líber Livro, 2006.

MEIRA, Luciano. Análise microgenética e videografia: ferramentas de pesquisa em psicologia cognitiva. Temas Psicológicos, Ribeirão Preto, SP, v. 2, n. 3, p. 59-71, dez. 1994. Disponível em: <http://pepsic.bvsalud.org/scielo.php?script=sci arttext\&pid=S1413-389X1994000300007\&lng=pt \&nrm=iso>. Acesso em: 12 fev. 2016.

MELLO, S. A. Infância e humanização: algumas considerações na perspectiva histórico-cultural. Perspectiva, Florianópolis, v. 25, n. 1, p. 83-104, jan./jun. 2007.

MELLO, S. A.; FARIAS, M. A. A escola como lugar da cultura mais elaborada. Educação, Santa Maria, RS, v. 35, n. 1, p. 53-68, jan./abr. 2010.

MINAYO, M. C. de S. Ciência, técnica e arte: o desafio da pesquisa social. In: MINAYO, M. C. de S.; DESLANDES, O. C. N.; GOMES, R. (Org.). Pesquisa social: teoria, método e criatividade. 21. ed. Petrópolis, RJ: Vozes, 1994. p. 9-29.

MOURA, M. O. de. Pesquisa colaborativa: um foco na ação formadora. In: BARBOSA, Raquel Lazzari Leite (Org.). Trajetórias e perspectivas da formação de educadores. São Paulo: UNESP, 2004. p. 257-284.

MUKHINA, V. Psicologia da idade pré-escolar. São Paulo: Martins Fontes, 1996.

NASCIMENTO, C. P. A organização do ensino e a formação do pensamento estético-artístico na teoria histórico-cultural. 2010. 250 f. Dissertação (Mestrado em Educação) - Programa de Pós-
Graduação em Educação da Universidade de São Paulo (USP), São Paulo, 2010.

PIAGET, J. A. Formação do símbolo na criança: imitação, jogo e sonho, imagem e representação. 3. ed. Rio de Janeiro: Zahar, 1978.

POSSENTI, S. Por que (não) ensinar gramática na escola. Campinas, SP: Mercado de Letras, 1996.

SCHNEUWLY, B.; DOLZ, J. Gêneros orais e escritos na escola. 3. ed. Campinas, SP: Mercado de Letras. 2004.

SILVA; A. A. C. da. ALVES, N. N. de L. A relação entre o desenvolvimento infantil e o processo de aquisição da linguagem escrita na educação infantil. ENCONTRO REGIONAL NORTE/NORDESTE/ CENTRO-OESTE SOBRE FORMAÇÃO DOCENTE PARA EDUCAÇÃO BÁSICA E SUPERIOR, 6., 2015, Brasília, DF. Anais... Brasília, DF: UnB, 2015. In: Disponível em: <http://scholar.google.com/ scholar_url?url=http://www.enforsupunb2015. com.br/congresso/files/artigo/1426329953. docx\&hl=pt->. Acesso em: 12 dez. 2015.

SMOLKA, A. L. B. A criança na fase inicial da escrita: a alfabetização como processo discurso. 13. ed. São Paulo: Cortez, 2012.

SOARES, M. Aprendizagem da língua materna: problemas e perspectivas. Em Aberto, Brasília, DF, v. 2, n. 12, p. 3-15, jan. 1983.

SOUZA, F. L. E. Práticas de letramento na educação infantil: o caso de uma escola da rede pública do Distrito Federal. 2015. 250 f. Dissertação (Mestrado em Processos de Desenvolvimento Humano e Saúde) - Programa de Pós-Graduação em Processos de Desenvolvimento Humano e Saúde da Universidade de Brasília (UnB), Brasília, DF, 2015.

VIANNA, H. M. Pesquisa em educação: a observação. Brasília, DF: Liber Livro, 2007.

VIÑAO FRAGO, A. Leer y escribir: historia de dos prácticas culturales. México D. F.: Fundación Educación, Voces y Vuelos, 1999.

VYGOTSKY, L. S. Obras Escogidas II. 2. ed. Madri: Visor, 2001.

Obras Escogidas III. 2 ed. Madri: Visor, 2000.

Psicologia pedagógica. São Paulo: Martins Fontes, 2004.

Quarta aula: a questão do meio na Pedologia. Psicologia USP, São Paulo, v. 21, n. 4, p. 681-701, 2010.

Recebido em: 16/01/2017 Aprovado em: 11/01/2018 